\title{
Toys Featured in Tools and Tools Featured in Toys
}

\author{
Zhang Tian-cheng ${ }^{1}$, Zhang Chun-yan ${ }^{2}$ \\ ${ }^{1} \mathrm{CNC}$ Engineering Department, Anhui Technical College of Mechanical and Electrical Engineering, Anhui Wuhu, China \\ ${ }^{2}$ School of Mechanical and Vehicle Engineering, Bengbu College , Anhui Bengbu, China
}

\begin{abstract}
Experience design and crossover development become one of the future directions. The trend of more convenient life highlights the need for the integrated design of tools and toys, and the rapid development of productivity, as a main driving force, makes the project possible. The emotionalization of tools and the practicality of toys shift during the evolution of the integrated design, which will enhance the user's sensory experience. More attention should be paid to the interaction of rational and affective thinking and crossover products, to promote the all-round development and more experience design, meanwhile, the industrial design should conform to the popular aesthetics.
\end{abstract}

\section{Introduction}

People's ultimate aim, in general, is to create a happy, healthy and peaceful life for each individual in various ways, such as the progress of human civilization, the development of science and technology as well as a lifetime's effort. [1] The human design civilization experiences a series of changes, from the unconscious tools design to the conscious service scheme, from the original society's "design for survival" to the experience design of the concept era, which are the outcomes of the rapid development in the industry; However, the development of product design has never denied the belief that individuals and groups should all satisfy the integration of practical and spiritual function.

The concept of toys featured in tools and tools featured in toys innovates the ideas. The syncretism of the function of tools and the easiness of toys is undoubtedly a perfect ending. Tools and toys mentioned in this article are different from the concept of dictionaries and other authoritative books. Tools are defined as the products that meet the practical needs of human beings, which provide practicability. Meanwhile, toys are products that can satisfy peoples' spirit and emotional needs, which focus on the spiritual function. The evolution of the reciprocal transformation of toys and tools is an epitome of the peoples' desires to pursue both good material life and spiritual life.

\section{Sensory and experiential design as needed}

The primitive meaning of the sensory and experiential design that adapts to the all-round development of human beings and to promote felicity, harmony and happiness, instead of luxury and isolation. The concept of toys featured in tools and tools featured in toys implies the deep integration of rational and emotional information, practica lity and emotionality, which reflects the ultimate value of human psychological needs and real goal around a series of people's psychology, behavior, emotional appeal.

\subsection{About needs}

(1) Definition of needs

Needs, in this article, is supposed to help people's production activities, to provide convenience in all aspects or to meet human's desire for better material and spiritual enjoyment. [2] From a psychological point of view, the concept of "needs" implies some form of "scarcity", "problem to solve" and "urgent desire". [3] Material enjoyment and spiritual enjoyment are the universal interests and pursuits of human existence.

(2) Real needs

The development of information technology not only isolates us from the real life, but also ignores the most basic human needs from the spiritual level. T. S. Eliot, a famous poet, once said, "Although television makes many people laugh at the same joke at the same time, it still makes people feel lonely." "We need to push forward the development of intelligence, and we want a balance between high technology and high emotion," John Naisbitt said in his book " Mind Set! ". [4] Hayao Miyazaki, a world animation master, said in his interview of "Spirited Away": We live in a "recreational" society. Adults are constantly seeking entertainment to fill the emptiness of the mind, and the phenomenon also embodies in the child. Excessive entertainment makes their perception passivated, and their creativity is diminished. [5] Adults use excessive or even low-level entertainment to fill gaps in the mind. In the child's world, the inflow of entertainment, the narrow

*Corresponding author: ${ }^{1}$ skgcztc@163.com, ${ }^{253849182 @ q q . c o m}$ 
living space, the passivation of perception and the lack of companionship, have reduced their talent for creativity. Therefore, we need to advocate the "true", "good" and "beauty" of the products and eliminate "false" "evil" and "ugly" at the same time. We need to restore the numbness of consciousness, wake up the sleeping creativity, and explore the more meaningful values in the human subconscious, in order to balance the material needs and spiritual needs of human beings. If we do so, it will be easier for us to discover people's healthy and harmonious life style, rather than stimulating the most primitive and foolish desires.

\subsection{Designs adapted to senses and experience}

\section{(1) Sensory design}

The so-called sense organs, generally refer to eye, ear, tongue, nose, body and so on, which have special physiological structures and functions, and are able to accept the different stimuli from the outside world and produce the senses of vision, hearing, taste, smell and touch, thus achieving psychological comfort and satisfaction of the needs for self-actualization.[6] Generally speaking, the functions of vision, hearing and touch account for $65 \%, 25 \%$ and $10 \%$ respectively[7]. Accordingly, human beings have attached so much pleasure for eyes, that they always make intentional or unintentional efforts to decorations when designing a product. So, in China, whether it is in the field of highend patented products or in the popular wholesale market, there is a superb collection of products claiming exterior attractiveness, which also shows the lack of innovation in product designs and technology, as well as the reality that the industrial designs are too exclusive but uncompetitive.

(2) Experiential design

In the field of biology, vision, hearing, taste, smell and touch constitute the main ways for human beings to understand and perceive the world. Through the indefinable combination of various senses, human beings experience the products, and they can even use synaesthesia, such as seeing the sound, smelling the shapes, touching the colors, hearing the tastes, etc., to guide their external and internal activities. At the same time, according to the actual needs of some special groups, such as women, children, the aged and the disabled, industrial designers should get breakthroughs from different sensory experiences, including the appearance, the functions, the modes of use, the positioning of products, the operational environment, the innovation of science and technology and so on, which will surely challenge the patience consciousness and habitual thinking of human beings. A large number of studies have shown that cross experience can actually bring a better and more unique feelings to human beings, so as to get the humanistic concern besides the actual use experience. For example, the zippers specially designed for the blind, has solved the problem that the normal persons can not get well-dressed quickly under the dim light; and another product for the blind, the voiced traffic lights, also make it safer for smartphone addicts to cross over the intersections.

As an analytical means of human psychological needs, sense and experience make us realize the common mode behind the toys featured in tools and tools featured in toys ---- sensory and experiential design based on practicality and emotionality: the tool-like toys, the toylike tools, as well as the dual identity of tools and toys, which provides possibilities for promoting the overall development of human mental health and expanding the space for industrial design.

\section{Toys featured in tools}

As one of the basic categories of products, the tool has been serving as the extension of human brains and physical limbs, and enhances their ability to adapt to the outside world. It is an important means and result of human practice. [8] Based on Maslow's theory of hierarchy of needs, Patrick Jordan, the director of the PHILPS Design Aesthetics Research Association, proposes three hierarchies of human needs for products: functionality, usability and happiness. Although this theory treats the various purposes of product designs in isolation, it interprets the purposes that humans impose to the products by verifying the functional beauty of modernism and beauty in form of postmodernism and digital era, and provides theoretical support for the concept of toys featured in tools.

\subsection{Essence of toys featured in tools}

The toys featured in tools means that, on the basis of the practicality, more emotional connotations should be given to the products, making the product not only rational and perceptual, but also practical and emotional. Such toys featured in tools can transmit their practical functions appropriately, and convey emotional resonance to humans, such as health, well-being, happiness, etc.. Li Zhengdao, a winner of Nobel Prize in Physics, once holds that, without emotions, can our wisdom create a new path? Without intelligence, can emotions achieve perfect results? They are likely to be non separable. If so, art and science are actually two sides of a coin, which originate from the noblest part of human activities and pursue profundity, universality and meaningfulness. Thus, being beneficial, interesting and meaningful has become the lifeblood of toys featured in tools.

\subsection{Status quo of the researches on toys featured in tools}

(1) Application status of toys featured in tools

Nowadays, the society has been stepping into the era of right brain, and the abundant tools have strengthened people's pursuit of spiritual life, such as appearance, sound, taste, smell, touch, character and so on, which is the reason for the elimination of traditional product designs. For example, the game functions, comprehensive functions and fashionable styles of mobile phones are emerging one after another; as long as 
conditions permit, private cars that are usually used as travel tools can be modified into luxury toys at will; the horse riding, boating, spinning wheel, even gliding parachute, hot air balloon and sailing ship, that are not often seen in ordinary people's lives, have gradually evolved into toys for experiential games. Interactivity, including multiplicity of connotations, diversification, convenience of use, miniaturization of sizes and sensory experience, is the future development trend of toys featured in tools, who bear the responsibility of making people feel healthy and happy.

(2) Manifestation patterns of toys featured in tools

The purposes of toys featured in tools can be summarized as making people feel a sense of health, well-being and happiness, however, there are many ways to realize it. The sensory and experiential design as needed provides a set of useful manifestation patterns for the toys featured in tools. Therefore, the appearance, sound, taste, smell, touch and character of the products constitute the main means to realize it, which also promotes the diversification of product designs. Among them, the inspection of interest is the most successful example of toys featured in tools. Due to the indifference of interpersonal relationship, life is often in danger of losing control, and worries and anxieties devour people's hearts. As a result, DIY products, which are randomly shaped according to consumers' preferences, satisfy people's psychological needs to a certain extent. The portable chopsticks, as shown in Figure 1, are made of soft metal, thus they may be turned into pipes, chopsticks, or even a ring that can be worn on the wrist like a bracelet. As it can be used whenever and wherever possible, the goals of significant decrease of the use of disposable chopsticks and protection of valuable natural resources can be achieved. Taking chopsticks as a prop, the environment as a scene, to perceive its connotation by firsthand experience will be propitious to change people's ways of living and behaving, thus inspiring more creative thoughts.

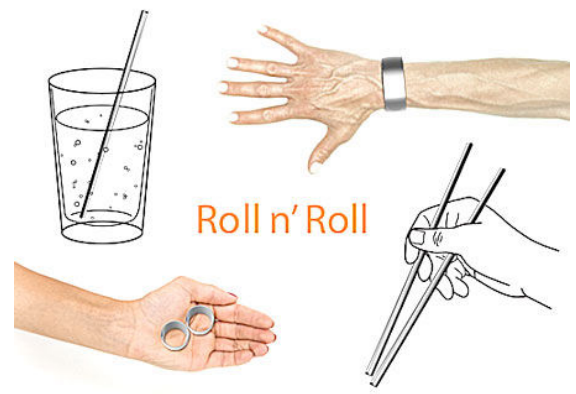

Fig.1 Portable chopsticks

\section{Toys featured in tools}

As far as traditional thinking is concerned, Chinese people generally believe that excessive attention to trivialities saps the will, and toys are exclusive to children. In Japan, the sales of adult toys accounts for about $65 \%$ of the annual market turnover of 900 billion yen. Most (84\%) adults between the age of 18 and 69 admit having toys, and nearly half of the persons investigated claim that they have more than 20 peripheral products of comics and animations. In the United States, more than $40 \%$ toys are designed for adults every year. In China, the young ones' demands for adult toys has already reached 50 billion yuan.[9] Toy design has long been an important category of industrial design traditionally. Now, featuring multiple identities, it has entered our daily life as both a popular cultural phenomenon and even a tool with educational function.

\subsection{Essence of tools featured in toys}

The concept of tools featured in toys requires to treat toys for the purpose of satisfying people's multiple demands in essence, endowing practicality to the toys that only please people in the spiritual level. In the process of meeting human spiritual and emotional needs, toys gradually integrate the appropriate practical value, and achieve the combination of emotionality and practicability. It can be said that, such toys serve as educational tools for children, and has the the effect of healing and pleasure for adults. Such toys will surely become an indispensable part to all stages of life. The essential characteristics of tools featured in toys are the interactivity that is intertwined with happiness, education, health, functionalization, security, science and technology, globalization, the all-aged design and integration.

\subsection{Application status and manifestation of tools featured in toys}

The development of instrumentalized toys has been a time-honored trend. According to the Encyclopedia, early toys are developed from self-defense and instincts. In many cultures, the first thing to teach children is how to use weapons, many physical games and athletic sports come from competitions and wars.[10] On the one hand, the development of science and technology, the abundance of materials and the complexity of consumption mentality, make traditional toys no longer win the hearts of all. On the other hand, the application of new materials and technologies has injected new vitality into the tools featured in toys. The rapid growth of everyday toys and animated peripheral products has prompted the instrumentalization of toys as the epoch features of product consumption and design.

(1) Everyday toys

Adding ordinary daily attributes to toys will greatly enrich the connotations of toys and broaden the designers' minds. For example, the robot girl serving in a dining room, the robot called Baymax greeting people at a bank, and the child watch with a positioning function, are all possess multiple functions of entertainment and education, as well as a great potential value. The design of building blocks of calendar, see Figure 2, is inspired by the spirit of building blocks and made of resin, an environmentally friendly material, and it tells people the date of any month in any year after random placement of numbers. This design not only makes people feel the joy of hands-on and restores the 
feelings of young people, but also reminds people of date. One object with multifunction is convenient, practical and environmental friendly.

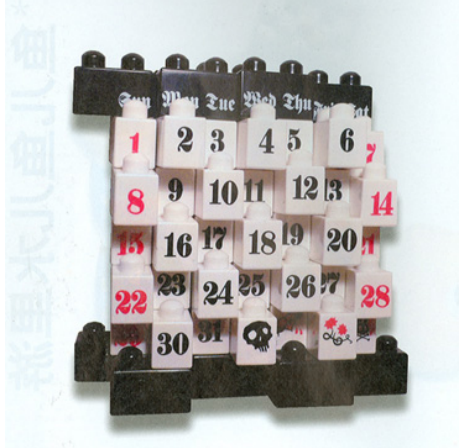

Fig.2 Building blocks of calendar

(2) Animated peripheral products

The emergence of animated peripheral products is inseparable from toys.[11] The so-called animated peripheral products, also known as animation derivatives, are collectively referred to as Hobby, which include all physical manifestations that are related to the animated images, and are divided into hard and soft peripheral products.[12] Although animated images only exist in the virtual world, they are in fact the Utopia in our subconscious mind, and are often able to transmit positive energy. As is shown in Figure 3, the Disguise Transformers watch is designed for children only. Featuring a built-in drive structure, it looks like a normal watch, however, in particular cases, especially under the call of self-defense, the watch can be turned into a Transformers. In a nutshell, it is not only a watch, but also a toy.

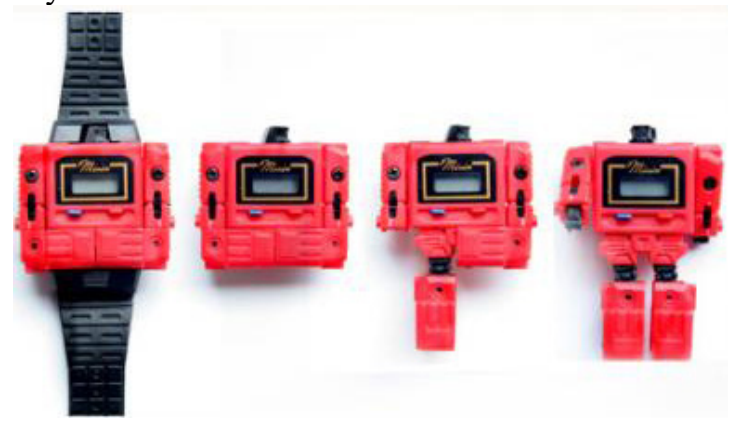

Fig.3 Disguise transformers watches

It is worth noting that the specific animated peripheral products have obvious characteristics of the regions and the times. With various external factors, such as the increasing age, the value orientation, etc., it is easy for them to be obsolete, especially in today's society that puts particular emphasis on personalized design and fast pace. A large number of eliminated animated peripheral products have become garbage. As long as there is an Andy, who will grow up, there will be abandoned toys. Nothing will keep unchanged forever. And time does not only lead toys to the tragic fate of being neglected, but also takes away too much of our childhood feelings.[13] This brings about another principle of product design, that the life cycle and the commodity circulation must be taken into account, for the purpose of cherishing resources and protecting environment; concerning about the green design of animated peripheral products is a major issue in the future.

\section{Conclusions}

As is known to all, what the industrial designers should do is not to make simple additions merely, in other words, they should try their best to achieve greater added value through industrial design. From the consumers' point of view, products must meet the multiple needs of human beings, so as to express the endless spiritual and material pursuit of human beings. Therefore, the toys featured in tools and the tools featured in toys should be regarded as an indispensable direction for human's pursuit of health, happiness and harmonious lives. The integration of tools and toys will become one of the important topics of future design. Holding the courage and consciousness to break through the exterior attractiveness, and bearing the responsibility of for the good of next generation, great importance must be attached to the cultural connotation of products, while giving them gorgeous appearances; when pursuing the value expression of the true, the good and the beautiful, the value guidance method of the false, the evil and the ugly have to be removed to the utmost of our power, and the practical function and emotional appeal must be integrated into one. This is a major issue for future designers.

\section{References}

1. Li Geng,The Aesthetic Turn of Mass Culture,Beauty \& Times[J],2007.10(321)

2. Kepu Wenzhai,2007(11)

3. Gao Nan,Methods and Cases of Industrial Design Innovation[M], Chemical Industry Press, 2006.1(1)

4. The Era of Right Brain Highlights the Management of Human Senses, Human Resources,2007.11(264)

5. Xu Jing \& Wang Yang, Reading -- World Classic Animation[M], Blossom Press, 2005.8(1)

6. Ren Lisheng, Design Psychology[M], Chemical Industry Press, 2005.8(1)

7. Zhang Ying,Visual Sense-False Sense-Toy[J], Art \& Design,2005.10(150)

8. Chen Hanqing,Product Design[M], Huazhong University of Science and Technology Press, 2005.11(1)

9. Choice, 2008(1)

10. Zhang Pei\& Wang Hongge, Toys and Innovative Design[M], Chemical Industry Press, 2006.2(1)

11. Zhou Lanping, History of Comic and Animation[M], Chongqing Publishing Group \& Chongqing Publishing House, 2007.4(1)

12. Zhao Juntao \&Tan Beilin, CorelDRAW \& Flash 8 Animation Art Design[M], Tsinghua University Press, 2007.1(1)

13. Sun Taotao, An Analysis of the Narrative Mode of Toy Story III $[\mathrm{J}]$, Art Science and Technology, 2015(5) 